\title{
Wistar Unilever, Rat Strain
}

National Cancer Institute

\section{Source}

National Cancer Institute. Wistar Unilever, Rat Strain. NCI Thesaurus. Code C76193.

A Wistar substrain that was disseminated to Glaxo Laboratory (UK) from the Wistar Institute in Philadelphia in 1933, then to the Dutch Institution for Nutrition (Amsterdam, The Netherlands) and maintained by Unilever Company (Vlaardingen, The Netherlands) from 1941. T his strain is now disseminated by Harland Nederland. The Wistar Unilever rat is an albino, genotype c, with pink eyes and very docile manner, making it a popular choice in multidisciplinary biomedical research worldwide. The breed is specifically involved in developmental toxicity and carcinogenesis studies as well as being used as an animal model for vitamin A deficiency in humans. 